\title{
Crescimento e produção do melão cultivado sob cobertura de solo e diferentes freqüências de irrigação
}

\author{
José F. de Medeiros ${ }^{1}$, Marcelo C. de C. Silva ${ }^{2}$, Francisco G. Câmara Neto ${ }^{3}$, Antônio H. B. de Almeida ${ }^{4}$, \\ Jean de O. Souza ${ }^{3}$, Maria Z. de Negreiros ${ }^{1} \&$ Silvana P. F. Soares ${ }^{3}$
}

\begin{abstract}
RESUMO
Objetivou-se, com este trabalho, avaliar índices de crescimento, fisiológicos e de produção, de quatro híbridos de meloeiros cultivados com e sem cobertura do solo e três freqüências de irrigação. Utilizaram-se dois experimentos conduzidos no período de junho a setembro de 2001, em Mossoró, RN. Num se cultivou usando solo nu e noutro, usando cobertura com filme de polietileno. Adotou-se o delineamento experimental em blocos completos casualizados com duas repetições por bloco. Utilizaram-se três freqüências de irrigação, com cada uma aplicada num bloco experimental. Estudaram-se os híbridos de melão cantaloupe, denominados PX3912947 (H1), Vera cruz (H2), Trusty (H3) e Torreon (H4). Maior área foliar foi obtida nos híbridos $\mathrm{H} 1$ e H2, independente da cobertura e frequêencia de irrigação. No sistema de plantio com cobertura do solo, a cultura do meloeiro aumentou o peso seco da parte vegetativa sem os frutos e suportou turno de regas maiores. Os híbridos $\mathrm{H} 2$ e H4 obtiveram, juntos, maior taxa de crescimento absoluto no solo descoberto, enquanto apenas o híbrido $\mathrm{H} 4$ alcançou maior taxa de crescimento relativo, neste solo. Os híbridos $\mathrm{H} 1$ e $\mathrm{H} 3$ produziram frutos grandes fora do padrão. A cobertura do solo proporcionou maior produtividade e peso médio dos frutos.
\end{abstract}

Palavras-chave: Cucumis melo L., desenvolvimento do melão, manejo de irrigação

\section{Growth and production of melon cultivated under soil covering and different frequencies of irrigation}

\begin{abstract}
The objective of this study was to evaluate growth, physiologic and production indices of four hybrids of melon crop cultivated with and without soil covering and three irrigation frequencies. Two experiments were conducted during the period of June to September, 2001, in Mossoró, RN, using soil with and without a covering of polyethylene film. The experimental design was in completely randomized blocks with two repetitions per block. Three irrigation frequencies were used, with each one applied in an experimental block. The hybrids of melon cantaloupe, denominated PX3912947 (H1), Vera Cruz (H2), Trusty $(\mathrm{H} 3)$ and Torreon $(\mathrm{H} 4)$ were studied. Larger foliar area was obtained in the hybrids $\mathrm{H} 1$ and $\mathrm{H} 2$, independent of soil covering and irrigation frequency. In the planting system with soil covering, the melon crop increased the dry weight of aerial parts without fruits and tolerated higher irrigation frequencies. The hybrids $\mathrm{H} 2$ and $\mathrm{H} 4$ presented higher rates of absolute growth in bare soil, while the hybrid $\mathrm{H} 4$ reached a higher relative growth rate in this soil. The hybrids $\mathrm{H} 1$ and $\mathrm{H} 3$ produced large fruits beyond the standard. The covering of soil resulted in higher productivity and greater mean weight of fruits.
\end{abstract}

Key words: Cucumis melo L., melon development, irrigation management

1 UFERSA, CP 137, CEP 59625-900, Mossoró, RN. Fone: (84) 3315 0557. E-mail: jfmedeir@ufersa.br

${ }^{2}$ Doutorando em Fitotecnia/UFV, CEP 36570-000. Viçosa, MG. Fone: (31) 3892 4106. E-mail: mdecastro70@yahoo.com.br

${ }^{3}$ Estudante de graduação em Agronomia/UFERSA, CP 137, CEP 59625-900, Mossoró, RN. Fone: (84) 3315 1799, E-mail: deag@ufersa.br

${ }^{4}$ M. Sc. Genética e Melhoramento de Plantas, CP 137, CEP 59625-900, Mossoró, RN. Fone: (84) 3315 0557, E-mail: deag@ufersa.br 


\section{INTRODUÇÃO}

O Pólo Agrícola Mossoró-Assu, em razão das condições edafoclimáticas propícias ao cultivo do meloeiro: solos franco-arenosos e classificação climática segundo Koeppen do tipo BSwh' (muito quente e com estação chuvosa no verão atrasando-se para o outono) ideal para o seu cultivo, de vez que tem a temperatura média de $27,4{ }^{\circ} \mathrm{C}$, precipitação pluviométrica média de $673,9 \mathrm{~mm}$ distribuída em no máximo cinco meses e umidade relativa média de 68,9\% (Carmo Filho et al., 1991), tem se destacado como a região maior produtora dessa fruta no país.

A cada ano, novos híbridos são introduzidos na região, tornando-se necessário o conhecimento do crescimento desses melões, visando melhorar as práticas de manejo. Devido ao comportamento diferenciado entre cultivares às condições ambientais e a necessidade de melhorar a produção em quantidade e qualidade, inúmeras tecnologias se vêm desenvolvendo e adaptando-se para a região com o objetivo de oferecer suporte a esta cultura destacando-se, dentre elas, a cobertura do solo, sobretudo depois da disponibilidade no mercado nacional e regional dos filmes plásticos, cuja aceitação é cada vez maior por parte de produtores e pesquisadores.

O uso de filmes plásticos na agricultura apresenta a facilidade de controle de ervas daninhas e melhor aproveitamento da água de irrigação, pois ocorre menor evaporação, reduzindo a aplicação da água. Outro aspecto positivo desta técnica é a obtenção de frutos com qualidade visual externa elevada; como desvantagens, têm-se o elevado custo do filme e a falta de conhecimento mais precisa para manejar a irrigação, quer seja na estimativa da evapotranspiração para essas condições, quer seja na definição de sua freqüência (Martins, 1996; Silva et al., 2005).

Ibarra et al. (2001) notaram que plantas de melão cultivadas sob cobertura plástica (filme de polietileno preto) apresentaram valores mais elevados de área foliar, fitomassa seca da parte aérea e taxa de crescimento relativo, que em solo descoberto; verificaram, ainda, rendimento total mais elevado em plantas cultivadas sob cobertura do solo. Também no meloeiro, Silva et al. (2005), perceberam que o híbrido Trusty, do tipo cantaloupe, alcançou maior produtividade quando cultivado em solo coberto com filme plástico. Entretanto, Martins et al. (1998) trabalhando com duas cultivares de me- lão, Melina e Amarelo, em ambiente protegido, não verificaram efeito positivo da cobertura do solo nos componentes de produção da cultura.

O manejo da irrigação é fator indispensável para o sucesso na produção da cultura de melão, tanto no que se refere à produtividade como à qualidade dos frutos. A temperatura, umidade relativa, insolação e velocidade do vento, são alguns parâmetros climáticos que, ao lado do estádio fenológico do melão, textura, cobertura do solo e índice de área foliar, definem a necessidade de água para a cultura e a freqüência de irrigação (Allen et al., 1998; Costa et al., 2000).

Devido a não evaporação da superfície do solo quando se utiliza a cobertura plástica espera-se uma redução na necessidade hídrica da cultura (Allen et al., 1998), entretanto, o maior crescimento da planta, tanto no acúmulo de matéria seca como no índice de área foliar, na presença da cobertura do solo com plástico (Costa et al., 2002), pode aumentar a demanda hídrica, o que pode alterar a freqüência de irrigação em relação ao sistema de produção convencional.

Assim, objetivou-se, com este trabalho, avaliar índices de crescimento, fisiológicos e de produção de quatro híbridos de meloeiros, cultivados com e sem cobertura do solo e três freqüências de irrigação.

\section{MATERIAL E MÉTODOS}

O experimento foi conduzido no período de junho a setembro de 2001, na área experimental da fazenda São João Ltda., localizada no km 4 da RN-15, no município de Mossoró, RN, com as coordenadas geográficas $5^{\circ} 10^{\prime} 35^{\prime \prime}$ de latitude Sul, $37^{\circ} 24^{\prime} 29^{\prime \prime}$ de longitude Oeste e $60 \mathrm{~m}$ de altitude, em um solo Luvissolo crômico, cujas análises química e física se encontram na Tabela 1.

Os dados climáticos foram coletados na Estação Meteorológica da Escola Superior de Agricultura de Mossoró (ESAM), que se localiza a $12 \mathrm{~km}$ da fazenda. Os valores médios observados durante o ciclo cultural para as temperaturas média, máxima e mínima diárias, umidade relativa do ar média diária, velocidade do vento a $2 \mathrm{~m}$ de altura e evapotranspiração de referência (ETo) calculada pela equação de Penman-Monteith FAO foram 27,7; 35,3 e 21,5 ${ }^{\circ} \mathrm{C} ; 59,0 \%$, $2,3 \mathrm{~m} \mathrm{~s}^{-1}$ e $6,0 \mathrm{~mm} \mathrm{~d}^{-1}$, respectivamente.

Tabela 1. Análises química e física do solo da área experimental, na presença e ausência de cobertura do solo cultivado com quatro híbridos de melão, em três freqüências de irrigação

\begin{tabular}{|c|c|c|c|c|c|c|c|c|}
\hline \multirow{3}{*}{ Cobertura } & \multirow{3}{*}{$\mathrm{pH}(1: 2,5) \mathrm{H}_{2} \mathrm{O}$} & \multicolumn{5}{|c|}{ Complexo Sortivo } & \multirow{3}{*}{$\begin{array}{c}\mathbf{P}^{*} \\
\left(\mathrm{mg} \mathrm{dm}^{-3}\right)\end{array}$} & \multirow{3}{*}{$\begin{array}{c}\text { Soma Base } \\
\left(\mathrm{cmol}_{\mathrm{c}} \mathrm{kg} \mathrm{dm}^{-3}\right)\end{array}$} \\
\hline & & $\mathrm{Ca}$ & $\mathrm{Mg}$ & K & $\mathrm{Na}$ & Al & & \\
\hline & & \multicolumn{5}{|c|}{$\left(\mathrm{cmol}_{\mathrm{c}} \mathrm{dm}^{-3}\right)$} & & \\
\hline Presente & 7,60 & 8,60 & 2,90 & 2,21 & 0,29 & 0,00 & 59,00 & 14,0 \\
\hline Ausente & 7,40 & 8,60 & 3,00 & 2,17 & 0,23 & 0,00 & 48,00 & 14,0 \\
\hline \multirow{2}{*}{ Profundidade (cm) } & \multicolumn{5}{|c|}{ Composição Granulométrica $\left(\mathrm{g} \mathrm{kg}^{-1}\right)$} & \multirow{2}{*}{\multicolumn{2}{|c|}{ Classificacão Textural }} & \multirow{2}{*}{ Densidade $\left(\mathrm{kg} \mathrm{dm}^{-3}\right)$} \\
\hline & Areia & \multicolumn{2}{|c|}{ Argila } & \multicolumn{2}{|c|}{ Silte } & & & \\
\hline $0-20$ & 734 & \multicolumn{2}{|c|}{172} & \multicolumn{2}{|c|}{94} & \multicolumn{2}{|c|}{ Franco arenoso } & 1,62 \\
\hline $20-40$ & 647 & & & & & \multicolumn{2}{|c|}{ Franco argilo-arenoso } & 1,52 \\
\hline
\end{tabular}


Foram instalados dois experimentos concomitantes numa mesma área usando o delineamento experimental em blocos completos casualizados com duas repetições por bloco. Os tratamentos corresponderam aos híbridos de melão cantaloupe denominados PX3912947 (H1), Vera cruz (H2), Trusty (H3) e Torreon (H4). Os experimentos diferiram pela presença (CP) ou ausência (CA) da cobertura do solo (polietileno dupla face preto/prateado) e os blocos corresponderam as diferentes freqüências de irrigação definidas pelo potencial matricial (média das profundidades de 15 e $30 \mathrm{~cm}$ ) que o solo deveria apresentar antes da irrigação, que foram para CP1 e CA1 aproximadamente -15, -10 e -15 kPa; para CP2 e CA2 - aproximadamente -20, - 15 e -20 kPa e para CP3 e CA3 - aproximadamente -30, -20 e -25 kPa respectivamente, até a floração, enchimento do fruto e maturação. Os turnos de rega para os períodos de 12-30, 30-45, 45-55, e 55-70 dias após a semeadura para os experimentos estão apresentados na Tabela 2.

Tabela 2. Turnos de rega médios na presença e ausência de cobertura do solo cultivado com quatro híbridos de melão, em três freqüências de irrigação. Mossoró, RN, ESAM, 2001

\begin{tabular}{|c|c|c|c|c|c|}
\hline \multirow{3}{*}{ Cobertura } & \multirow{3}{*}{ Freqüência } & \multicolumn{4}{|c|}{ Período (dias após semeadura) } \\
\hline & & $12-30$ & $30-45$ & $45-55$ & $55-70$ \\
\hline & & \multicolumn{4}{|c|}{ Turno de Rega } \\
\hline \multirow{3}{*}{ Presente } & CP1 & 3 & 2 & 1 & 2 \\
\hline & CP2 & 5 & 3 & 2 & 3 \\
\hline & $\mathrm{CP} 3$ & 7 & 4 & 3 & 4 \\
\hline \multirow{3}{*}{ Ausente } & CA1 & 2 & 1 & 1 & 1 \\
\hline & CA2 & 4 & 2 & 2 & 2 \\
\hline & CA3 & 6 & 3 & 3 & 3 \\
\hline
\end{tabular}

Os experimentos foram conduzidos em área com $4.200 \mathrm{~m}^{2}$, dotado com sistema de irrigação por gotejamento, dividido em duas glebas de $30 \times 70 \mathrm{~m}$ sendo os emissores de 2,3 $\mathrm{L} \mathrm{h}^{-}$ 1 espaçados $2,0 \times 0,3 \mathrm{~m}$. As parcelas experimentais corresponderam a uma fileira de $70 \mathrm{~m}$, sendo a área útil para coleta de plantas e para avaliação da produtividade correspondente a $12 \mathrm{~m}$ de fileira de plantas. A cobertura do solo correspondeu o envolvimento do camalhão com plástico preto/prateado (dupla face), ressaltando-se que a última face estava voltada para cima. As duas áreas foram preparadas com uma aração e duas gradagens para formar os canteiros, enquanto o espaçamento utilizado para o plantio foi de 2,0 x 0,3 m, com apenas uma planta por cova.

Uma parte da adubação foi aplicada em fundação e a outra por fertirrigação, seguindo a exigência da cultura; nesta primeira, aplicaram-se $150 \mathrm{~kg} \mathrm{ha}^{-1}$ da formulação (06:24:12) e 2 $\mathrm{Mg} \mathrm{ha}^{-1}$ de composto orgânico (esterco, palha de arroz e cama de galinha). Os totais de N, P e K aplicados via fertirrigação foram de 93, 126 e $348 \mathrm{~kg} \mathrm{ha}^{-1}$, respectivamente.

O controle fitossanitário e as capinas também foram realizados de acordo com o manejo adotado pela fazenda. Inseticidas específicos foram aplicados por ocasião do surgimento de pragas, sobretudo da mosca branca (Bemisia argentifolii) e minadora (Liriomyza sp.); realizaram-se pulverizações para controle de Oídio e Micosphaerella, que atacou o híbrido PX3912947 depois de 40 dias após a semeadura.

Para cada tratamento do manejo da irrigação, a evapotranspiração da cultura foi estimada a partir da evapotranspiração de referência, através da equação de Penman-Monteith FAO utilizando dados de uma estação climatológica situada a 12 Km e coeficiente de cultura (Kc) (Allen et al., 1998). A lâmina total de irrigação foi obtida pela razão entre a evapotranspiração da cultura e a eficiência da irrigação, adotada como 0,91.

Foram amostradas plantas (apenas parte aérea) aos 20, 27, 34, 41, 51 e 70 dias após a semeadura, em $12 \mathrm{~m}$ de fileira previamente selecionada para este fim; após a coleta, foram conduzidas até o laboratório, local em que se lhes separavam as folhas e caules e se procedeu à contagem de folhas por planta e medição da área foliar por planta, utilizando-se um integrador de área foliar, modelo LI 3100. Por sua vez, as partes das plantas foram separadas, pesadas e acondicionadas em sacos de papel, levadas à estufa de circulação forçada de ar, onde foi mantida a temperatura de $70{ }^{\circ} \mathrm{C}$, durante 48 a $72 \mathrm{~h}$, para posterior pesagem da fitomassa seca da parte vegetativa.

A taxa de crescimento relativo foi avaliada em diversas fases de desenvolvimento da cultura, segundo metodologia de Benincasa \& Leite (2002), quantificada com a variação de incremento da matéria seca vegetal da parte vegetativa, entre duas amostras coletadas em um intervalo de tempo de aproximadamente uma semana, utilizando-se a expressão:

$$
\mathrm{TCA}=\frac{\mathrm{PS} 1-\mathrm{PS} 2}{\mathrm{~T} 1-\mathrm{T} 2}
$$

em que:

TCA - taxa de crescimento absoluto

PS1 e PS2 - peso seco inicial e final, respectivamente, de cada intervalo de tempo

T1 e T2 - tempo inicial e final, respectivamente, de cada período

A taxa de crescimento relativo foi calculada de acordo com a produção de uma nova matéria seca da parte vegetativa, com base na fitomassa seca já existente, para as diversas fases de desenvolvimento da cultura.

$$
\mathrm{TCR}=\frac{\mathrm{Ln}(\mathrm{PS} 2)-\mathrm{Ln}(\mathrm{PS} 1)}{\mathrm{T} 1-\mathrm{T} 2}
$$

em que:

\section{TCR - taxa de crescimento relativo}

Ln - logaritmo neperiano do peso seco nos tempos $\mathrm{T}_{1}$ e $\mathrm{T}_{2}$. T1 e T2 - tempo inicial e final, respectivamente, de cada período

Fez-se a análise multivariada para dados repetidos no tempo, usando-se o procedimento GLM do SAS â (Lima, 1996) e para dados com curvas de evolução não paralelas, procedeuse à análise univariada para cada época da coleta. A comparação das médias foi realizada através do teste de Tukey a 
5\% de probabilidade (Gomes, 2000). Para dados de produção realizou-se análise conjunta de experimentos (Gomes, 2000).

\section{RESULTADOS E DISCUSSÃO}

Em condições de solo sem cobertura com plástico, houve diferença significativa entre as freqüências de irrigação estudas para área foliar das cultivares de melão apenas aos 51 dias (Tabela 3) onde a freqüência média de irrigação (CA2) proporcionou área foliar superior às demais. Quanto aos híbridos, o Vera Cruz, juntamente com o PX3912947, apresentaram maior área foliar durante todo o ciclo para o cultivo em solo descoberto. Verifica-se que no solo coberto, os híbridos de melão foram indiferentes as freqüências de irrigação estudadas, quanto à área foliar (Tabela 3). Ainda observa-se que o híbrido Vera Cruz desenvolveu a maior área foliar, fato que tinha sido observado em diferentes épocas para o solo descoberto. Nos dois sistemas de cultivo, com e sem cobertura do solo, o hídrido Trusty tendeu a apresentar menor área foliar ao longo do ciclo cultural.

De uma maneira geral, verifica-se que a partir dos 34 dias após a semeadura, em média, a área foliar das cultivares de melão tendeu a ser superior quando o cultivo se deu sob solo com cobertura plástica, o que está de acordo com resultados

Tabela 3. Valores médios* da área foliar $\left(\mathrm{cm}^{2}\right.$ planta $\left.^{-1}\right)$ na ausência e presença de cobertura do solo cultivado com quatro híbridos de melão, em três freqüências de irrigação. Mossoró, RN, ESAM, 2001

\begin{tabular}{|c|c|c|c|c|c|}
\hline \multirow{2}{*}{ Tratamento } & \multicolumn{5}{|c|}{ Idade da Planta (dias) } \\
\hline & 20 & 27 & 34 & 41 & 51 \\
\hline \multicolumn{6}{|c|}{ Na ausência de cobertura do solo } \\
\hline \multicolumn{6}{|l|}{ Freqüência } \\
\hline CA1 & 72,9 a & $376 a$ & $1171 \mathrm{a}$ & $4800 \mathrm{a}$ & $7667 \mathrm{~b}$ \\
\hline CA2 & $63,1 \mathrm{a}$ & $415 \mathrm{a}$ & $1452 \mathrm{a}$ & $5416 \mathrm{a}$ & $11889 a$ \\
\hline CA3 & $60,4 \mathrm{a}$ & $415 \mathrm{a}$ & $1334 \mathrm{a}$ & 4809 a & $8046 \mathrm{~b}$ \\
\hline \multicolumn{6}{|l|}{ Híbrido } \\
\hline PX3912947 & $83,0 \mathrm{a}$ & $524 \mathrm{a}$ & $1908 \mathrm{a}$ & 9449 a & $8118 a b$ \\
\hline Vera Cruz & $73,5 \mathrm{ab}$ & $419 a b$ & $1528 \mathrm{a}$ & $5072 \mathrm{ab}$ & 11127 a \\
\hline Trusty & $42,3 \mathrm{~b}$ & $298 b$ & $1059 \mathrm{a}$ & $3718 b$ & $6980 \mathrm{~b}$ \\
\hline Torreon & $63,0 a b$ & $366 \mathrm{~b}$ & $1181 \mathrm{a}$ & $5794 \mathrm{a}$ & $10579 a b$ \\
\hline CV (\%) & 22,39 & 21,17 & 8,38 & 16,78 & 27,34 \\
\hline \multicolumn{6}{|c|}{ Na presença da cobertura do solo } \\
\hline \multicolumn{6}{|l|}{ Freqüência } \\
\hline CP1 & $51,9 \mathrm{a}$ & $501 \mathrm{a}$ & $1512 \mathrm{a}$ & $5501 \mathrm{a}$ & 11538 a \\
\hline CP2 & $51,9 a$ & $510 a$ & $2008 \mathrm{a}$ & $6799 a$ & 12920 a \\
\hline CP3 & $52,1 \mathrm{a}$ & $497 \mathrm{a}$ & $1884 \mathrm{a}$ & $6005 a$ & $11337 \mathrm{a}$ \\
\hline \multicolumn{6}{|l|}{ Híbrido } \\
\hline РX3912947 & $45,3 \mathrm{a}$ & $473 a b$ & $1808 \mathrm{a}$ & $4378 \mathrm{~b}$ & 10227 a \\
\hline Vera Cruz & $66,8 \mathrm{a}$ & $420 \mathrm{a}$ & $2088 \mathrm{a}$ & $6587 \mathrm{a}$ & $15942 \mathrm{a}$ \\
\hline Trusty & $42,5 \mathrm{a}$ & $420 \mathrm{~b}$ & $1358 \mathrm{a}$ & $5914 a b$ & $10761 \mathrm{a}$ \\
\hline Torreon & $53,2 \mathrm{a}$ & $487 \mathrm{ab}$ & $1953 \mathrm{a}$ & $7529 a$ & 10796 a \\
\hline CV (\%) & 37,85 & 27,35 & 26,68 & 17,49 & 16,57 \\
\hline
\end{tabular}
diferem entre si $(0,05)$ pelo teste de Tukey obtidos por Ibarra et al. (2001) para o meloeiro e com Klar \& Jadoski (2002) para a cultura do pimentão.

$\mathrm{Na}$ ausência de cobertura do solo, ocorreu diferença significativa entre as freqüências de irrigação para fitomassa seca da parte vegetativa, onde se verificou que o maior peso seco foi encontrado na freqüência CA2; a partir do $27^{\circ}$ até o $51^{\circ}$ dia; com relação aos híbridos, destacaram-se o PX3912947 e o Vera Cruz, mostrando que para esta característica ambos sobressaem em solos descobertos e com freqüência de irrigação intermediária (Tabela 4). Percebe-se que no solo coberto, o peso seco da parte vegetativa, foi indiferente às freqüências de irrigação; já no que diz respeito aos híbridos, o PX3912947 obteve o pior desempenho quanto a esta característica, quando comparado com os demais.

Tabela 4. Valores médios* do peso seco da parte vegetativa (g planta ${ }^{-1}$ ) na ausência e presença de cobertura do solo cultivado com quatro híbridos de melão, em três freqüências de irrigação. Mossoró, RN, ESAM, 2001

\begin{tabular}{|c|c|c|c|c|c|c|}
\hline \multirow{2}{*}{ Tratamento } & \multicolumn{6}{|c|}{ Idade da Planta (dias) } \\
\hline & 20 & 27 & 34 & 41 & 51 & 70 \\
\hline \multicolumn{7}{|c|}{ Na ausência da cobertura do solo } \\
\hline \multicolumn{7}{|l|}{ Freqüência } \\
\hline CA1 & $0,51 \mathrm{a}$ & $2,62 \mathrm{a}$ & 9,35 a & $37,2 \mathrm{a}$ & $70,9 \mathrm{~b}$ & $73,3 \mathrm{a}$ \\
\hline CA2 & $0,45 a$ & $2,77 \mathrm{a}$ & $12,44 \mathrm{a}$ & $42,7 \mathrm{a}$ & $104,2 \mathrm{a}$ & $62,4 a b$ \\
\hline CA3 & $0,47 a$ & $2,86 \mathrm{a}$ & 9,58 a & $37,5 a$ & $72,3 \mathrm{~b}$ & $49,2 \mathrm{~b}$ \\
\hline \multicolumn{7}{|l|}{ Híbrido } \\
\hline PX3912947 & $0,60 \mathrm{a}$ & $3,63 \mathrm{a}$ & $11,30 \mathrm{a}$ & $47 \mathrm{a}$ & $78 \mathrm{a}$ & $64 a$ \\
\hline Vera Cruz & $0,52 a b$ & $2,98 \mathrm{ab}$ & $11,68 \mathrm{a}$ & $40 \mathrm{a}$ & $95 \mathrm{a}$ & $71 \mathrm{a}$ \\
\hline Trusty & $0,33 a b$ & $1,95 \mathrm{c}$ & $10,78 \mathrm{a}$ & $27 \mathrm{~b}$ & $61 \mathrm{a}$ & $44 a$ \\
\hline Torreon & $0,46 \mathrm{~b}$ & $2,43 b c$ & $8,05 \mathrm{a}$ & $42 a$ & $97 \mathrm{a}$ & $68 \mathrm{a}$ \\
\hline CV (\%) & 25,23 & 7,25 & 27,99 & 19,02 & 29,12 & 28,58 \\
\hline \multicolumn{7}{|c|}{ Na presença da cobertura do solo } \\
\hline \multicolumn{7}{|l|}{ Freqüência } \\
\hline $\mathrm{CP} 1$ & $0,35 a$ & $3,33 a$ & $11,7 \mathrm{a}$ & $42,9 \mathrm{a}$ & 81,9 a & 74,8 a \\
\hline $\mathrm{C} 21$ & $0,36 \mathrm{a}$ & $3,04 \mathrm{a}$ & $12,8 \mathrm{a}$ & $51,1 \mathrm{a}$ & $113,1 \mathrm{a}$ & $114,7 \mathrm{a}$ \\
\hline CP3 & $0,36 a$ & $3,14 \mathrm{a}$ & $13,9 a$ & $47,2 \mathrm{a}$ & $106,8 \mathrm{a}$ & $74,1 \mathrm{a}$ \\
\hline \multicolumn{7}{|l|}{ Híbrido } \\
\hline PX3912947 & $0,34 \mathrm{a}$ & $3,06 \mathrm{a}$ & $10,6 \mathrm{a}$ & $35,1 \mathrm{~b}$ & $102,0 \mathrm{a}$ & $123,3 \mathrm{a}$ \\
\hline Vera Cruz & $0,45 a$ & $3,95 \mathrm{a}$ & $15,2 \mathrm{a}$ & $52,0 \mathrm{a}$ & $117,4 \mathrm{a}$ & 78,3 a \\
\hline Trusty & $0,27 a$ & $2,75 a$ & $11,7 \mathrm{a}$ & $46,0 a b$ & $92,1 \quad a$ & 65,4 a \\
\hline Torreon & $0,37 a$ & $2,93 \mathrm{a}$ & $13,8 \mathrm{a}$ & $55,3 \mathrm{a}$ & 90,9 a & $84,3 \mathrm{a}$ \\
\hline CV (\%) & 40,57 & 26,25 & 33,26 & 17,52 & 32,17 & 70,21 \\
\hline
\end{tabular}

* Médias seguidas das mesmas letras na coluna entre freqüências de irrigação ou híbridos não diferem entre si $(0,05)$ pelo teste de Tukey

Verifica-se, que em média, o peso da matéria seca vegetativa foi maior quando os melões foram cultivados na presença de cobertura do solo a partir dos 34 dias após a semeadura, concordando, neste caso, com Ibarra et al. (2001), haja vista terem encontrado que plantas de melão cultivadas sob cobertura plástica (filme de polietileno preto) apresentaram valores mais elevados de fitomassa seca vegetativa e, com Sarmento (2001), que encontrou uma fitomassa vegetativa $29,62 \%$ superior no solo coberto, quando comparado com o solo descoberto.

Para taxa de crescimento absoluto vê-se que, quando cultivados em solo descoberto, os híbridos Vera Cruz e Torreon 
obtiveram maior taxa de crescimento quando comparados com os demais híbridos. Quanto ao solo com filme plástico, o Vera Cruz tendeu a ter uma taxa de crescimento maior, desempenho diferente do PX3912947, que resultou na pior taxa de crescimento em solo coberto (Tabela 5). A taxa de crescimento relativo também está representada na Tabela 5 e mostra que no solo coberto o híbrido Torreon obteve pior desempenho desta característica apenas aos 41-51 dias, mas para o solo descoberto este híbrido obteve uma das maiores taxas de crescimento relativo. Também verifica-se que a taxa de crescimento relativo foi maior quando se usou o solo descoberto para todos os híbridos, dados estes diferentes dos relatados por Ibarra et al. (2001), ao verificarem valores mais elevados de taxa de crescimento relativo, quando plantas de melão foram cultivadas com cobertura de solo.

Tabela 5. Médias da taxa de crescimento absoluto* e relativo na presença e ausência de cobertura do solo cultivado com quatro híbridos de melão, em três freqüências de irrigação. Mossoró, RN, ESAM, 2001

\begin{tabular}{|c|c|c|c|c|c|c|}
\hline \multirow{2}{*}{ Cobertura } & \multirow{2}{*}{ Híbrido } & \multicolumn{5}{|c|}{ Idade da Planta (dias) } \\
\hline & & $20-27$ & 27-34 & $34-41$ & $41-51$ & $51-70$ \\
\hline \multicolumn{7}{|c|}{ Taxa de crescimento absoluto $\left(\mathrm{g} \mathrm{d}^{-1}\right)$} \\
\hline \multirow{5}{*}{ Presente } & PX3912947 & $0,78 b$ & $2,15 d$ & $7,04 \mathrm{c}$ & $21,07 b$ & $9,08 \mathrm{a}$ \\
\hline & Vera Cruz & $1,00 \mathrm{a}$ & $3,22 \mathrm{a}$ & $11,39 b$ & $25,44 \mathrm{a}$ & $3,02 \mathrm{c}$ \\
\hline & Trusty & $0,71 \mathrm{~b}$ & $2,57 \mathrm{c}$ & $11,25 b$ & $17,98 \mathrm{c}$ & $4,61 \mathrm{~b}$ \\
\hline & Torreon & $0,73 b$ & $3,10 b$ & $12,35 \mathrm{a}$ & $17,43 \mathrm{c}$ & $9,57 \mathrm{a}$ \\
\hline & PX3912947 & $0,87 \mathrm{a}$ & $2,19 a$ & $10,76 \mathrm{a}$ & $15,42 b$ & $6,61 \mathrm{a}$ \\
\hline \multirow{3}{*}{ Ausente } & Vera Cruz & $0,70 \mathrm{a}$ & $2,49 a$ & $8,63 \mathrm{a}$ & $24,77 \mathrm{a}$ & $9,90 \mathrm{a}$ \\
\hline & Trusty & $0,46 \mathrm{a}$ & $2,52 \mathrm{a}$ & $5,35 b$ & $15,43 b$ & $7,79 a$ \\
\hline & Torreon & $0,56 \mathrm{a}$ & $1,60 \mathrm{a}$ & $10,30 \mathrm{a}$ & $21,07 \mathrm{a}$ & $9,06 \mathrm{a}$ \\
\hline CV (\%) & & 33,5 & 17,1 & 29,8 & 18,5 & 31,6 \\
\hline \multicolumn{7}{|c|}{ Taxa de crescimento relativo $\left(\mathrm{g} \mathrm{g}^{-1} \mathrm{~d}^{-1}\right)$} \\
\hline \multirow{4}{*}{ Presente } & PX3912947 & $0,648 \mathrm{a}$ & $0,340 \mathrm{c}$ & $0,355 \mathrm{a}$ & $0,278 \mathrm{a}$ & $0,039 \mathrm{a}$ \\
\hline & Vera Cruz & $0,630 \mathrm{~b}$ & $0,375 b$ & $0,374 \mathrm{a}$ & $0,236 b$ & $0,014 \mathrm{a}$ \\
\hline & Trusty & $0,649 a$ & $0,436 \mathrm{a}$ & $0,423 \mathrm{a}$ & $0,189 \mathrm{c}$ & $0,025 \mathrm{a}$ \\
\hline & Torreon & $0,604 \mathrm{~b}$ & $0,433 a$ & $0,419 a$ & $0,186 \mathrm{~d}$ & $0,051 \mathrm{a}$ \\
\hline \multirow{4}{*}{ Ausente } & PX3912947 & $0,519 a$ & $0,317 \mathrm{c}$ & $0,426 b$ & $0,166 \mathrm{a}$ & $0,051 \mathrm{a}$ \\
\hline & Vera Cruz & $0,497 a$ & $0,392 \mathrm{~b}$ & $0,368 \mathrm{c}$ & $0,271 \mathrm{a}$ & $0,046 \mathrm{a}$ \\
\hline & Trusty & $0,504 a$ & $0,485 a$ & $0,294 d$ & $0,251 \mathrm{a}$ & $0,058 \mathrm{a}$ \\
\hline & Torreon & $0,480 \mathrm{a}$ & $0,328 \mathrm{c}$ & $0,496 \mathrm{a}$ & $0,246 \mathrm{a}$ & $0,049 \mathrm{a}$ \\
\hline CV (\%) & & 32,90 & 16,75 & 30,62 & 18,27 & 30,64 \\
\hline
\end{tabular}

diferem entre si $(0,05)$ mesmas letras, na

Verifica-se na Tabela 6 que, em média, o híbrido PX3912947 e o Trusty produziram frutos com pesos maiores, embora fora do tamanho aceito pelo mercado de exportação, que devem ter massa inferior a $1250 \mathrm{~g}$. Foi baixa a produtividade do PX3912947, por sua maior sensibilidade a doenças fúngicas. Em se falando sobre freqüência de irrigação, os híbridos não apresentaram diferença quanto à produtividade e peso médio dos frutos. A cobertura do solo proporcionou maior produtividade e peso médio dos frutos, resultados estes que concordam com Bradenberger \& Wiendenfeld (1997), quando verificaram incremento na produção de melão, em média, de
Tabela 6. Médias* de produtividade e peso do fruto de quatro híbridos de melão submetidos à presença e ausência de cobertura do solo e três freqüências de irrigação. Mossoró, RN, ESAM, 2001

\begin{tabular}{ccc}
\hline $\begin{array}{c}\text { Tratamentos } \\
\text { Cobertura }\end{array}$ & Peso do fruto $\mathbf{( k g )}$ & Produtividade $\left(\mathbf{m g ~ h a}^{-1}\right)$ \\
\hline Ausente & $1229 \mathrm{~b}$ & $23,10 \mathrm{~b}$ \\
\hline Presente & $1453 \mathrm{a}$ & $32,12 \mathrm{a}$ \\
\hline Freqüência & & \\
\hline Uma & $1375 \mathrm{a}$ & $30,88 \mathrm{a}$ \\
\hline Duas & $1281 \mathrm{a}$ & $25,38 \mathrm{a}$ \\
\hline Três & $1368 \mathrm{a}$ & $26,57 \mathrm{a}$ \\
\hline Híbrido & & \\
\hline PX3912947 & $1425 \mathrm{ab}$ & $21,60 \mathrm{~b}$ \\
\hline Vera Cruz & $1168 \mathrm{c}$ & $27,57 \mathrm{a}$ \\
\hline Trusty & $1579 \mathrm{a}$ & $31,02 \mathrm{a}$ \\
\hline Torreon & $1192 \mathrm{bc}$ & $30,27 \mathrm{a}$ \\
\hline
\end{tabular}

* Médias seguidas das mesmas letras na coluna entre freqüências de irrigação ou híbridos não diferem entre si $(0,05)$ pelo teste de Tukey

$42 \%$ em 1994 e $27 \%$ no ano de 1995 , com a utilização da cobertura do solo em relação ao solo descoberto, com Morais et al. (2004), que evidenciaram maior produtividade comercial e total nos tratamentos com filme de polietileno prateado e amarelo, com Silva et al. (2005), que verificaram aumento na produção do meloeiro e, com Hora et al. (2001), quando evidenciaram aumento na produção de pimentão; porém discorda de Martins et al. (1998) ao concluírem que a cobertura do solo não proporcionou diferença significativa nos componentes de rendimento do meloeiro e Souza et al. (2001), que não encontraram diferenças entre a produção de pepino cultivado com e sem polietileno, bem como Sampaio et al. (1999) na cultura do tomate. Provavelmente o híbrido cultivado em solo coberto tenha sofrido menos competição com ervas daninhas, pois neste ambiente não se verificam invasoras, quando comparado com o solo nu, e aproveitou melhor a água quando comparado com o solo desnudo, pois neste ambiente não se verifica evaporação, mas somente transpiração da planta. Desta forma, as plantas do tratamento com cobertura de solo apresentavam melhores condições para o aproveitamento da água disponível que, ao ser reduzida gradualmente durante a secagem do solo, provavelmente tenha sofrido um estresse menor, fazendo com que obtivesse melhor desenvolvimento, tanto da área foliar quanto da fitomassa, refletindo, conseqüentemente, na produtividade do meloeiro.

\section{CONCLUSÕES}

1. O melhor manejo de irrigação para o crescimento do meloeiro foi aquele que se adotou um turno de rega médio, tanto para o solo coberto como para o solo descoberto, ou seja, irrigação a cada dois dias no período de crescimento dos frutos.

2. Maior área foliar foi obtida nos híbridos PX3912947 e Vera Cruz, independente da cobertura e freqüência de irriga- 
ção.

3. No sistema de plantio com cobertura do solo a cultura do meloeiro aumentou o peso seco da parte vegetativa sem os frutos e suportou turno de regas maiores.

4. Os híbridos Vera Cruz e Torreon obtiveram, juntos, maior taxa de crescimento absoluto no solo descoberto, enquanto apenas o híbrido Torreon alcançou maior taxa de crescimento relativo, neste solo.

5. Os híbridos PX3912947 e Trusty produziram frutos maiores e fora do exigido pelo mercado.

6. A freqüência de irrigação não afetou a produtividade dos híbridos de melão cantaloupe.

7. A cobertura do solo proporcionou produtividade e peso maiores dos frutos.

\section{AGRADECIMENTOS}

Os autores agradecem à Fazenda São João Ltda., pelo fornecimento de toda a infra-estrutura imprescindível à instalação e condução do experimento.

\section{LITERATURA CITADA}

Allen, R.G.; Pereira, L.S.; Raes, D.; Smith, M. Crop evapotranspiration: guidelines for computing crop water requirements. Rome: FAO. Irrigation and Drainage Paper, 56, 1998. 300 p.

Benincasa, M.M.P; Leite I.C. Fisiologia vegetal. Jaboticabal: FUNEP, 2002. 169p.

Brandenberger, L.; Wiendenfeld, B. Physical characteristics of mulches and their impact on crop response and profitability in muskmelon production. HortTechnology, Alexandria, v.7, n.2, p.165-169, 1997.

Carmo Filho, F.; Espínola Sobrinho, J.; Maia Neto, J.M. Dados meteorológicos de Mossoró (janeiro de 1989 a dezembro de 1990). Mossoró: ESAM, FGD, 1991. 110 p. Coleção Mossoroense, Série C, 630 .

Costa, F.A.; Medeiros, J.F.; Negreiros, M.Z.; Bezerra Neto, F.; Porto, D.R.Q.; Chaves, S.W.P.; Dantas, K.N. Rendimento de melão cantaloupe em diferentes coberturas de solo e lâminas de irrigação. Caatinga, Mossoró, v.15, n.1/2, p.49-55, 2002.

Costa, N.D.; Dias, R.C.S.; Faria, C.M.B.; Tavares, S.C.C.H.; Terao, D. Petrolina-EMBRAPA. Empresa Brasileira de Pesquisa Agropecuária Semi-Árido, Avaliação de cultivares de cebola em Petrolina., p.37-39, 2000. Circular Técnica, 59.

Gomes, F.P. Curso de estatística experimental. 14.ed., Piracicaba: ESALQ. 2000. 644p.
Hora, R.C.; Souza, R.A.R.; Faria Junior, M.J.A. Cultivo de pimentão em diferentes condições de ambiente, com uso de mulching plástico. Horticultura Brasileira, Brasília, v.19, suplemento CD-Rom, 2001.

Ibarra, L.; Flores, J.; Díaz-Pérez, J.C. Growth and yield muskmelon in response to plastic mulch and row covers. Scientia Horticulturae, Coah, v.87, n.1-2, p.139-145, 2001.

Klar, A.E.; Jadoski, S.O. Efeitos da irrigação e da cobertura do solo por polietileno preto sobre as características morfológicas do pimentão. Irriga, Botucatu, v.7, n.3, p.154-167, 2002.

Lima, C.G. Análise de dados longitudinais provenientes de experimentos em blocos casualizados. Piracicaba: ESALQ, 1996. 126p. Tese Doutorado

Martins, S.R. Desafios da plasticultura brasileira: limites sócioeconômicos e tecnológicos frente as novas e crescentes demandas. Horticultura Brasileira, Brasília, v.14, n.2, p.133138, 1996.

Martins, S.R.; Peil, R.M.; Schwengber, J.E.; Assis, F.N.; Mendez, M.E.G. Produção de melão em função de diferentes sistemas de condução de plantas em ambiente protegido. Horticultura Brasileira, Brasília, v.16, n.1, p. 24-30, 1998.

Morais, E. R. C. de; Maia, C. E.; Lima Júnior, O. J. de; Negreiros, M. Z. de; Medeiros, J. F. de; Espínola Sobrinho, José; Leitão, M. de M. V B R; Oliveira, F. de A. Crescimento de melão cantaloupe torreon cultivado com diferentes cores de mulch e lâminas de irrigação nas condições de Mossoró, RN. In: Congresso Brasileiro de Olericultura, Horticultura Brasileira, 44, 2004, Campo Grande. Anais.....? Brasília: v.22, n.2, 2004. Suplemento1

Sampaio, R.A.; Fontes, P.C.R.; Sediyama, C.S. Resposta do tomateiro à fertirrigação potássica e cobertura plástica do solo. Pesquisa Agropecuária Brasileira, Brasília, v.34, n.1, p.21-30, 1999.

Sarmento, D.H.A. Crescimento de meloeiro sob diferentes níveis de salinidade de água de irrigação, com e sem cobertura do solo. Mossoró: ESAM, 2001. 35p. Monografia Graduação

Silva, M.C.C.; Medeiros, J.F.; Negreiros, M. Z.; Sousa, V.F. Produtividade de frutos do meloeiros sob diferentes níveis de salinidade da água de irrigação, com e sem cobertura do solo. Horticultura Brasileira, Brasília, v.23, n.2, p. 202-205, 2005.

Souza, R.A.R.; Hora, R.C.; Faria J.R.M.J.A. Cultivo de pepino em ambiente protegido, com diferentes níveis de sombreamento e cores de mulching. Horticultura Brasileira, Brasília. v.19, n.2, p.287, 2001. Suplemento CD-Rom 